\title{
Students' Participation And Its Relationship To Success In An Interactive Learning Environment
}

\author{
Binod Nainabasti*, David T. Brookes*, and Yuehai Yang ${ }^{\dagger}$ \\ *Department of Physics, Florida International University, 11200 S.W. $8^{\text {th }}$ St., CP 204, Miami, FL 33199 \\ + Department of Physics, California State University, Chico, Chico, CA 95929
}

\begin{abstract}
The context of our study is a calculus-based, studio-format introductory college physics course implementing the Investigative Science Learning Environment (ISLE). We have gathered data that allows us to quantify students' participation in three broad areas of the physics class: In-class learning activities, class review session that happened at the beginning of every class, and the informal learning community that formed outside of class time. Using video data, classroom observations, and students' self-reports, we quantified students' participation in these three aspects of the class throughout a single semester. We investigated the relationship between students' participation and their success in the course as measured by their FCI gain, exam scores, and scores on out-of-class assignments. Our results reveal that different aspects of the class play distinct roles in learning. Students who participated more in class review sessions ended up with better conceptual understanding. Self-reported hours of study outside of class was significantly correlated with success on out-of-class assignments.
\end{abstract}

Keywords: Participation, Learning Communities, Network Analysis PACS: 01.40.Fk, 01.40.Ha

\section{INTRODUCTION}

Considerable effort has already been expended to reform introductory Science, Technology, Engineering and Mathematics (STEM) courses under the assumption that traditional lecture-based instruction is ineffective and causes many STEM students to drop out [1]. Reformers believe that STEM courses should help students to integrate basic concepts into conceptual frameworks, link prior learning to new knowledge, and develop scientific reasoning to problem solving skills that support the application of concepts to new situations. They also believe that these goals are rarely realized for the majority of students in the traditional lecture model [1]. In order to overcome this situation, numerous researchers, government agencies and many other concerned agencies have called for the reform of standard lecture delivery by incorporating active learning in the classroom [2].

Active learning is a pedagogy in which students are encouraged to build up their learning autonomously. Interaction in active learning is effective in promoting more favorable attitudes toward learning, more positive relationships among students, greater academic achievement and increased persistence in STEM courses and programs [3]. Reformed curricula are trying to implement highly interactive and studentcentered learning environments in formal settings. However, there is little research about what sorts of interaction behavior students should practice to excel.
In this paper we are going to address the following research question: What sort of relationships exist between how students behave when they engage in various activities inside and outside of class and their success in the course, as measured by conceptual gain, exam score and effort score (students' scores on assignments completed outside of class time)?

\section{THEORETICAL FRAMEWORK}

There are two theoretical approaches to learning that are most relevant to our research. They are the participationist framework and constructivist learning theory.

In the participationist framework, learning is an ongoing process of transformation of participation in which people contribute support and direction in shared endeavors [4]. Participation theory helps us to recognize the bidirectional interaction between learning and students' identity. People believe that transformation of knowledge occurs through participation as "the idea that learning and development occur as people participate in the sociocultural activities of their community, transforming their understanding, roles and responsibilities as they participate" [4]. Interaction has been recognized as one of the most important components of learning experiences in student-centered courses. Interactions provide opportunities for students to learn to negotiate meaning and to become members of a learning community [5]. 
In social constructivist learning theory, researchers need to understand clearly the nature of interaction to increase the effectiveness of interactions in learning [6]. By recognizing the role of participation in learning Lave and Wenger suggest that: "The understanding to be gained from engagement can be extremely varied depending on the form of participation" [7]. It is these theoretical perspectives that motivate us to explore more deeply the role of participation in learning in an interactive learning environment.

\section{METHODOLOGY}

Participants for this study were drawn from students enrolled in an introductory physics I (mechanics) with calculus course at Florida International University in Fall 2013. This course was an integrated lab and lecture, implementing the Investigative Science Learning Environment (ISLE) philosophy [8] with thirty students in a studio-format class. The seating arrangement in the classroom consisted of 5 tables, each seating two groups of 3 students. The ISLE course operated as a collaborative learning setting and focused on conceptual reasoning and development of scientific habits of mind [8].

We gathered two distinct categories of data: (1) Data that allowed us to evaluate students' success in the course. This includes (a) individual students' gains on the Force Concept Inventory (FCI) [9], (b) students' overall course grades that we divided into two parts (i) Averaged exam score, comprised of two mid-terms and a cumulative final exam and (ii) Effort score: This score was based on three assignments completed outside of class time. They were homework, weekly journals, and lab reports. Their contributions to effort score were $40 \%, 20 \%$, and $40 \%$ respectively. (2) Data that allows us to quantify students' participation in three aspects of the class; (a) In-class Learning Activities, (b) class Review Session that happened at the beginning of every class and (c) the Informal Learning Community that formed outside the class time.

Learning Activities (LA): We videotaped a number of episodes throughout the semester of students working together in groups on specific learning activities. Six episodes were selected because their content was closely related to exam questions (2 from each exam). We categorized students' behavior in learning activities into four categories (described in Table 1.) and coded them into these four categories in 30 -second intervals. We coded 30 videos of which each was on average 20 minutes long in total. A single code was given for each 30-second time segment based on a superseding policy which is defined as follows: Code 1 (interacting) is always first, code 2 (off-topic) second, code 3 (writing/drawing) third and code 4 (uncodable) fourth. In detail, if a student was involved in interacting related to the assigned activity, we assigned them code 1 no matter how much time they spent interacting during that 30 -second interval. We assigned code 2 for a time interval only if there were no audible words related to the physics topic, but the student was involved in an off-topic conversation. We assigned code 3 if there were no audible words related to physics or off-topic conversations, but the student was writing or drawing on paper or whiteboards. When behaviors of students did not fit any of these first three categories, then we assigned them code 4.

Videos of LA were coded by two coders. Randomly selected samples were chosen to evaluate inter-rater reliability. On these samples a Cohen's Kappa of 0.78 was achieved.

TABLE 1. Coding scheme for learning activities

\begin{tabular}{c|c|l}
\hline Code & Categories & \multicolumn{1}{c}{ Description } \\
\hline 1 & Interacting & $\begin{array}{l}\text { Communicating with other } \\
\text { students or instructors in audible } \\
\text { words regarding the physics } \\
\text { subject. }\end{array}$ \\
\hline 2 & Off-topic & $\begin{array}{l}\text { Communicating with other } \\
\text { students or instructors in audible } \\
\text { words about anything but the } \\
\text { subject. }\end{array}$ \\
\hline 3 & Writing/ & $\begin{array}{l}\text { Writing or drawing on papers or } \\
\text { whiteboards without speaking to } \\
\text { others. }\end{array}$ \\
\hline 4 & Uncowing & $\begin{array}{l}\text { Behaviors/activities that do not fit } \\
\text { any of the three specific categories } \\
\text { above. }\end{array}$ \\
\hline
\end{tabular}

Review Session (RS): Each class started with a review session where the entire class worked together and anyone could participate. Review session was structured around two questions "what did we learn last class?" and "did anything remain unclear?" Sessions usually lasted 15-20 minutes and were largely student-directed with minimal intervention from the instructor. We coded the review session in real time without videotaping according to the coding scheme described in Table 2 and adopted the same superseding policy as in LA. Each student was assigned a single code for the entire review session.

Informal Learning Community (ILC): We asked students to self-report every week "who they worked with" and "how much time they spent working on physics" outside of class. The "who worked with whom" data allowed us to build up a social network picture of the ILC that forms outside of class-time. To quantify participation in the ILC formed outside of 
class, we applied a PageRank centrality measure on aggregated student network data. PageRank is a link analysis algorithm with the purpose of quantifying the importance of a node within the network. In our study each node represents a student. So, a student can acquire a high PageRank by having many students naming him/her or by having a few students with a high PageRank naming him/her. [10]. A network analysis package called Igraph is used to calculate Pagerank Centrality in R [11].

TABLE 2. Coding scheme for Review Session

\begin{tabular}{c|c|l}
\hline Code & Categories & \multicolumn{1}{c}{ Description } \\
\hline 1 & Participating & $\begin{array}{l}\text { Engaging in reviewing activities } \\
\text { in different ways. E.g.: } \\
\text { Answering, explaining, } \\
\text { presenting, challenging ideas; as } \\
\text { well as facilitating, questioning, } \\
\text { active listening and responding } \\
\text { to others. }\end{array}$ \\
\hline 2 & Disengaged & $\begin{array}{l}\text { Engaging in activities not related } \\
\text { to review session. For example: } \\
\text { texting, surfing online, doing } \\
\text { homework. }\end{array}$ \\
\hline 3 & Note-taking & $\begin{array}{l}\text { Taking notes about the subject } \\
\text { under review. }\end{array}$ \\
\hline 4 & Uncodable & $\begin{array}{l}\text { Sitting with no evidence of any } \\
\text { active involvement. }\end{array}$ \\
\hline
\end{tabular}

To investigate the relationship between students' success and their participation in LA, RS, and ILC, we applied Pearson correlation in cases when both dependent and independent variables satisfied four assumptions of Pearson's correlation [12]. In cases when a variable was not normally distributed (such as students' PageRank centrality measures) Spearman Rank Correlation was adopted for the analysis. In our analysis, measures of participation include interacting in LA, participating in RS and PageRank centrality in ILC outside the class. To check the correlation we treated students' success in the course (FCI gain, Effort Score, Exam Scores) as dependent variables and coding data from learning activities, review session and PageRank centrality in the out-of-class network as independent variables.

\section{RESULTS}

Table 3 shows the distribution of codes of students' behaviors in LA and RS. We then examined the relationship between students' participation in LA, RS, and ILC and their success as quantified by FCI gain, exam score and effort score. We also wanted to consider whether prior physics knowledge (quantified by students' FCI pre-score) would bias students' participation coming into the class. The results of this analysis are presented in Table 4 row 1 and suggest that students who come in the class with better conceptual understanding do not necessarily participate more than others.

TABLE 3: Average distribution of codes of students' behaviors in LA and RS

\begin{tabular}{c|c|c|c|c}
\hline Code & 1 & 2 & 3 & 4 \\
\hline LA & $55 \%$ & $7 \%$ & $12 \%$ & $26 \%$ \\
\hline RS & $43 \%$ & $11 \%$ & $9 \%$ & $37 \%$ \\
\hline
\end{tabular}

Results in Table 4 demonstrate that participation in different settings have varying levels of impact on different measures of students' success. Participation in LA, RS, and ILC have highest impacts on exam score, FCI gain, and effort score respectively.

TABLE 4: Pearson's and Spearman's correlation coefficient between different forms of participation and student success

\begin{tabular}{|c|c|c|c|}
\hline $\begin{array}{c}\text { Performa } \\
\text { nce }\end{array}$ & $\begin{array}{l}\text { Participation } \\
\text { in } \mathrm{LA}^{\dagger}\end{array}$ & $\begin{array}{l}\text { Participation } \\
\text { in } \mathrm{RS}^{\dagger}\end{array}$ & $\begin{array}{l}\text { Participation } \\
\text { in } \text { ILC }^{\dagger}\end{array}$ \\
\hline $\begin{array}{l}\text { Pre FCI } \\
\text { Score }\end{array}$ & $r_{p}=-0.11$ & $\mathrm{r}_{\mathrm{p}}=0.12$ & $r_{\mathrm{s}}=-0.28$ \\
\hline $\begin{array}{l}\text { Effort } \\
\text { Score }\end{array}$ & $\mathrm{r}_{\mathrm{p}}=0.27$ & $r_{p}=-0.37^{*}$ & $\mathrm{r}_{\mathrm{s}}=0.45^{*}$ \\
\hline $\begin{array}{l}\text { Exam } \\
\text { Score } \\
\end{array}$ & $\mathrm{r}_{\mathrm{p}}=0.43^{*}$ & $r_{p}=0.34$ & $\mathrm{r}_{\mathrm{s}}=0.44^{*}$ \\
\hline FCI Gain & $r_{p=0.38}$ & $\mathbf{r}_{\mathrm{p}}=\mathbf{0 . 5 7 * *}$ & $r_{s}=-0.004$ \\
\hline \multicolumn{4}{|c|}{$\begin{array}{l}* \mathrm{p}<0.05, * * \mathrm{p}<0.005, \text { number of observation } \mathrm{N}=30 \\
\mathrm{r}_{\mathrm{s}} \text { : Spearman's, } \mathrm{r}_{\mathrm{p}}: \text { Pearson's Correlation Coefficient. } \\
\dagger \text { "Participation" means interacting in LA, participating in } \\
\text { RS and PageRank centrality in ILC outside the class. }\end{array}$} \\
\hline
\end{tabular}

TABLE 5: Pearson's correlation coefficient between offtopic, disengagement, hours of study, and success

\begin{tabular}{c|c|c|c}
\hline & $\begin{array}{c}\text { Off-topic } \\
\text { in LA }\end{array}$ & $\begin{array}{c}\text { Disengage } \\
\text { ment in RS }\end{array}$ & $\begin{array}{c}\text { Hours of } \\
\text { Study }\end{array}$ \\
\hline FCI Gain & -0.21 & $-0.42 *$ & -0.13 \\
\hline Effort Score & $-0.47 *$ & -0.14 & $\mathbf{0 . 5 8 * *}$ \\
\hline Exams Score & -0.30 & $-\mathbf{0 . 5 3} * *$ & 0.23 \\
\hline \multicolumn{4}{|c|}{$* 0.05, * * \mathrm{p}<0.005, \mathrm{~N}=30$}
\end{tabular}

Besides 'interacting' in LA and 'participation' in RS, we examined the role of other behavioral categories in student success. Table 5 shows the relationships of off-topic in LA and disengagement in RS, with students' success. When we checked the relationship between writing/drawing and note-taking with performance, we did not find any significant relationships. We also examined the relationship between reported hours of study outside of class and student success. We believe hours of study to be a 
measurement of student effort outside of class. The significant correlation between hours of study and effort score supports this viewpoint. We suspected that homework was the most time consuming assignment outside of class time, as compared to journal and lab reports. The strong relationship between homework score and reported hours of study outside the class (Figure 1) supports this idea.

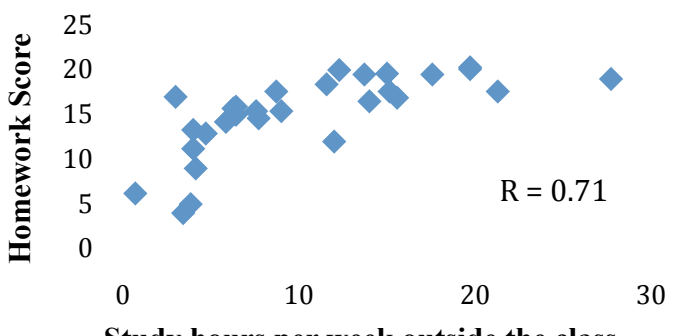

Study hours per week outside the class

FIGURE 1: Relationship between homework score and study hours per week outside the classroom.

\section{DISCUSSION \& CONCLUSION}

There are a number of interesting findings in our results. First, within the limited statistical power of our study, only participation in RS plays a significant role in gains in conceptual understanding. We suggest that this surprising result may be because RS was a rather unique class activity in which we observed students often engaged in intense communal "making-sense-of" ideas explored in the previous class with minimal intervention from the instructor. Students were free and willing to raise the questions that revealed their lack of understanding. Those questions were communally debated, only deferring to the instructor when an impasse was reached.

Second, it is interesting to see that hours of study outside of class are not significantly related to exam performance and FCI gain, but are significantly related to effort score. Our suspicion is that this was because most of students' endeavors outside of class were being devoted to completing homework and lab assignments. The relatively strong correlation between homework scores and hours of study (Figure 1) supports this idea. Participation in the informal learning community is marginally correlated to effort score, suggesting a picture in which the ILC serves as a "support network" for students helping them to get assignments done.

In future work we will take a closer look at the "uncodable" category. Students' codes fall in this category a substantial percentage of the time. It is unclear what these students are doing. Often they may be off-topic: students who were on their computer or smartphone, but we could not see what they were doing were placed in this category. But other times students were observed to be staring (apparently at nothing in particular) and may have actually been thinking about the physics subject. We may only be able to examine their participation qualitatively, using a questionaire to survey them after they have completed the course. We are also going to analyze the same students' participation patterns in one more semester. This analysis will allow us to make more convincing suggestions for learning how to interact and collaborate effectively with each other in a highly interactive learning environment.

\section{ACKNOWLEDGMENTS}

We would like to thank all members of PER Group at FIU for their feedback and encouragement. This research is supported by NSF grant \# 0802184.

\section{REFERENCES}

1. NRC (2003), Improving Undergraduate Instruction in STEM, National Academies Press, Washington, DC.

2. NSF (1996), Shaping the Future: New Experiences for Undergraduate Education in STEM, Arlington, VA.

3. R.M. Felder, G.N. Felder, and E.J. Dietz, Eng. Educ. 98, 469-480 (1998).

4. B. Rogoff, Apprenticeship in Thinking: Cognitive Development in Social Context (Oxford University Press, New York, 1990).

5. E. Brewe, L. Kramer, and G. O’Brien, Changing Participation Through Formation of Student Learning Communities, edited by C. Singh, M. Sabella and S. Rebello, AIP Conference Proceedings, Portland, OR, 2010, pp. 85-88.

6. L.S. Vygotsky, Mind in Society: The development of higher mental processes (Harvard University Press, Cambridge, MA 1978)

7. J. Lave, and E. Wenger, Situated Learning: Legitimate Peripheral Participation, (Cambridge University Press, Cambridge, U.K., 1991)

8. E. Etkina, and A. Van Heuvelen, "Investigative Science Learning Environment-A Science Process Approach to Learning Physics," in Research-Based Reform of University Physics, edited by E. F. Redish, and P.J. Cooney, (American Association of Physics Teachers, College Park, MD, 2007), Reviews in PER Vol. 1

9. D. Hestenes, M. Wells, and G. Swackhamer, Force Concept Inventory, Phys. Teach. 30, 141-158 (1992).

10. J.Bruun and E. Brewe, Phy. Rev. ST Phys. Educ. Res. 9, 020109 (2013)

11. G. Csardi, and T. Nepusz. The igraph software package for complex network research, International Journal Complex System, 1695, 1-9 (2006)

12.http://symynet.com/fb/quantitative_research_methods/Stati stics/assumptions_correlation/intro.htm 